\title{
A social-ecological systems approach is necessary to achieve Land Degradation Neutrality
}

\begin{abstract}
Viewing humans as drivers of change operating outside the natural environment is unhelpful for defining interventions that effectively manage change and complexity. Indeed, there is now broad agreement that environmental governance needs to consider integrated socialecological systems (SES) in order to tackle the world's grand challenges of land degradation. This requires a more differentiated, innovative approach that considers how changes in SES shape the functioning of land systems as a whole, and the synergies and trade-off these changes may produce. In this study, we identify and discuss some of the ways SES science and practice can inspire progress towards land degradation neutrality (LDN) outcomes in an integrated manner, through synthesis of literature and relevant documents related to the United Nations Convention to Combat Desertification (UNCCD). We do these by considering: (i) how LDN has been approached to date and the challenges likely to undermine progress towards achieving it; and (ii) an SES-based LDN approach relevant to the neutrality agenda, in particular, by describing how LDN might be thought of differently through an SES lens. We argue that an SES approach focusing on: (i) "people as part of nature", not "people and nature"; and (ii) the frame of reference against which neutrality can be assessed across temporal and spatial dimensions, is necessary to both inform policy and guide actions of the different groups involved in avoiding and combating land degradation. Such an (integrated) approach adds a dimension (to achieving neutrality goals) not previously explored in sustainable land management and LDN research. Important next steps in operationalising the SES-based LDN approach involve empirical and field case studies, requiring interdisciplinary, mixed method techniques.
\end{abstract}

Keywords: Social-ecological systems; Land degradation neutrality; SDGs; Sustainable land management; Natural capital, Baselines

\section{Introduction}

Humanity depends on land-based natural capital for life support, but anthropogenic activities are modifying land resources and the ecosystem functions and services they deliver in profound ways across the globe (Verberg et al., 2013). Tackling land management challenges in the 21st century requires a new understanding of the complex interactions between land systems and human societies, as well as an appreciation of the evolving notion of humans as nature (Torday and Miller, 2015). In particular, the sustainability of the world's land systems cannot be achieved without considering land degradation neutrality (LDN) interventions in social-ecological systems (SES) contexts (Cowie et al., 2018). LDN is enshrined in target 15.3 in the Sustainable Development Goals (SDGs) and can be defined as a state where "the amount and quality of land resources necessary to support ecosystem functions and services and enhance food security remain stable or increase within specified temporal and spatial scales and ecosystems" (UNCCD, 2016; 8). An SES context presupposes that promoting and maintaining well-functioning land ecosystems depends not only on politically-driven initiatives to avoid, reduce and/or reverse land degradation, but also requires land managers/institutions to ensure humans relate to, care for, and value ecosystems under efficient allocation of rights and privileges across time and locations (Orr et al., 2017). Indeed, sustainable land management (SLM) cannot be achieved separately from the livelihoods of land-dependent communities (Reed et al., 2015), or from the management of other socio-economic sources of wellbeing (such as financing green urbanisation) (Liu et al., 2013). More than ever, integrated SES approaches are needed to foster the achievement of LDN within a rapidly re-aligning global environmental change and sustainable development policy context. 
The concept of social-ecological systems (Ostrom, 2009) - also referred to as coupled human and natural systems (Liu et al., 2007) or coupled human-environment systems (Turner et al., 2003) - offers a powerful lens for framing interlinked human and ecological systems, putting into focus people's dependence on nature and their ethical obligations towards it (Fischer et al., 2015). An SES itself is a type of complex adaptive system composed of two primary subdomains: a human society and economy on the one hand, and a biological ecology on the other (Chapin et al., 2009). Using an SES approach implies engaging the coupled human-natural systems in ways that are useful to the different communities of resource managers. A concern for many of these communities is an improved state of human society and ecosystems. Indeed, an SES approach offers a novel interdisciplinary platform to integrate different views and dimensions of global land system changes (Leslie et al., 2015). This approach in the context of LDN is predicated on the notion that SLM resides in the condition and operation of human systems and ecological systems, including the response capacities and system feedbacks from land restoration and rehabilitation interventions (Verburg et al., 2015). The approach has matured during recent decades giving rise to new insights about synergies and trade-offs between human society and nature across different scales (Lambin and Meyfroidt, 2010), as well as advancing linkages between science and policy/practice (Liu et al., 2013).

As the intensity of interactions between humans and nature increases in scale and scope, understanding of the roles that SES can play in the pursuit of LDN is becoming more and more important (Orr et al., 2017). This is necessary to successfully overcome mounting land degradation threats and the associated social and economic challenges. Although SES offers guidance on how to think about the dynamics of land systems within human-social and ecological systems, it rarely (if ever) has been integrated in approaches to advance LDN in multiple localities in a clearly explicit manner that considers humans as part of nature. We argue that viewing humans as drivers of change operating outside the natural environment is unhelpful for defining interventions that effectively manage change and complexity (Raymond et al., 2013). As such, a step-change is needed in re-defining how LDN is pursued, as well as how human society and nature are conceptualised, in order to guide actions of the different actors involved in avoiding and combating land degradation. In this study, we identify and discuss ways in which SES science and practice can inspire progress towards LDN outcomes in an integrated manner, through synthesis of literature and relevant documents related to the United Nations Convention to Combat Desertification (UNCCD). We do these by examining how LDN has been approached to date, and the challenges likely to undermine progress towards achieving it (Section 2). We then introduce an SES-based LDN approach relevant to the LDN agenda, in particular, by describing how LDN might be thought of differently through an SES lens (Section 3). Findings from this study (summarised in Section 4) are useful for land management professionals and development actors that seek to utilise an SES-based LDN approach in their work, as well as researchers keen to advance the theoretical underpinnings of SES science to guide practical actions towards a well-functioning environment.

\section{Land Degradation Neutrality as a new paradigm for sustainable land management}

Land degradation covers at least $23 \%$ of terrestrial areas globally, increasing at the rate of 5 10 million ha annually (Stavi and Lal, 2015), and affects about 1.5 billion people globally (Gnacadja, 2012). Degradation is a state whereby the quantity and quality of land remain unstable or decline within specific spatiotemporal scales and ecosystems (Lal et al., 2012). Degradation involves the reduction of current and/or future biological productivity and decrease in capacity of land ecosystems to produce benefits from a particular land use under a specified form of land management (Grainger, 2015). This encompasses deterioration in quality and/or decline in quantity, leading to partial or total loss of one or more land ecosystem functions/services (UNCCD, 2017). Land Degradation Neutrality (LDN) represents an urgent and comprehensive politically-driven action to address degradation. It is an essential SDG target (15.3) requiring on-going or existing land degradation to be 
balanced by restoration/rehabilitation and sustainable land management, on-site or off-site. LDN aims to advance sustainable protection of land ecosystems and biodiversity and stabilise (or even increase) the amount of productive lands globally by 2030 , and as such increase food security and reduce poverty among highly ecosystem-dependent populations (Barkemeyer et al., 2015; Safriel, 2017).

Before LDN emerged in the international political arena in 2012, the UNCCD considered SLM as essential to prevent, mitigate and reverse degradation. But SLM has experienced slow uptake, partly because its targets and indicators are largely project-, site-and nationspecific (Lal et al., 2012). The inclusion of LDN as an SDG target helps to address the problem of slow SLM uptake, as well as enabling the merging of SLM and restoration/rehabilitation actions (Orr et al., 2017). Thus, neutrality is promoted to catalyse a global shift in land stewardship to avoid degradation of new land areas, and to ensure unavoidable degradation is offset or balanced by restoring/rehabilitating an equal amount of already degraded land (Gnacadja, 2012).

Previous management approaches related to land view humans as external drivers (masters and users of natural capital) of change that damage natural resources (Raymond et al., 2013). A utilitarian and exploitative perspective emphasising limitless resources and human dominion over nature shaped the management of natural systems before the mid- $20^{\text {th }}$ century (Margerum, 1995). This traditional command-and-control management approach enabled reactionary, top-down hierarchal processes, and was thought to encourage maximum sustainable yield of resources and a somewhat steady-state resource management (Born and Sonzogni, 1995). From the 1980s there was a transformation in worldview which spurred global awareness of the finite nature of the natural resource base. This led to social re-orientation and research on new approaches for environmental conservation and sustainability (Westley et al., 2011). Integrated environmental management (IEM), grounded in a theoretical view that ecological systems, including land, are complex, dynamic and constantly evolving, heralded a shift in management that conflicts with previous conventional, prescriptive management approaches. IEM supports the use of holistic, adaptive, and inclusive approaches to manage natural resources as a component of human/social- systems (Margerum, 1999).

As such, IEM led to the emergence of: (i) co-management approaches - emphasising stakeholder participation and collaboration for effective governance, and the sharing of power and responsibilities in environmental stewardship between institutions, managers and resource users, often located at different governance levels (i.e. the polycentric system mentioned in Ostrom (2010)); and (ii) adaptive management - based on learning-by-doing as a way to overcome uncertainty and complex challenges inherent in human-nature systems. The latter is fuelled by: complex, progressing and unforeseen climate change impacts on land-based systems that will increasingly need a precautionary approach to regulate land uses (Reed and Stringer, 2016); and anticipation of a likely increase in climate uncertainties, making quantitative judgements to regulate land use difficult in the short- to medium-term (see also European Commission, 2000). The precautionary approach is therefore maturing "into an ethical principle" in dealing with environmental issues (COMEST, 2005) and in this particular case, with LDN; (iii) a combined adaptive co-management approach, which is a bottom-up, emergent and self-organising process emphasising local stakeholder collaboration, social learning and knowledge co-generation as key to adapting management plans, actions and objectives over time to maximise their relevance (Armitage et al., 2008). Although adaptive co-management approaches offer solutions that improve upon earlier utilitarian and exploitative views of natural resources, today's complex environmental change issues (including spatiotemporal scale complexities, conflicting stakeholder perspectives (e.g. in terms of cultural and spiritual miscommunication), abrupt changes of vulnerable natural systems, and challenges of cross-disciplinary coupling) have meant that new 
approaches for resource management, including land/soil, are needed (see also Ostrom, 2010).

Approaches for tackling degradation and pursing LDN encompass two complementary actions (drawn from previous management approaches): (i) effective management of currently non-degraded lands in ways that sustainably maintain the amount and quality of land; and at the same time, (ii) restoring or rehabilitating already degraded lands in ways that halt further losses, and return land's productivity on the medium to long-term to a desired state that will depend on national circumstances. Such a desired state meets the needs of local communities and serves the expectations of a nation's vision for sustainable development (Akhtar-Schuster et al., 2017). These actions, overall, aim to offset losses such that the annual rate of recovery equals that of degradation, so that a state of neutrality is attained, stabilising the area of global productive lands (Cowie et al., 2018).

Although LDN is an emergent and evolving paradigm that reflects the vision of [national] land-related sustainable development targets, there is no consensus regarding the means to implement/achieve it. For example, it is unclear to what extent the two complementary actions are likely to create incompatible visions across varying scales. Also, it is unclear what exactly constitutes degradation in terms of distinguishing "between already degraded but stable land and land on an active degradation trajectory" (Akhtar-Schuster et al., 2017, p. 8). Conceiving land degradation as a decline (change) in the amount and quality of land resources necessary to support human life presupposes that change and degradation are most times treated synonymously (Ritsema et al., 2005). Yet, pinning down exactly when to say land degradation has happened is less explicit (in particular it is unclear whether to focus on changes in land cover, productivity and/or carbon storage, which encompass the global indicators agreed by the UN to assess progress towards LDN) (Sims et al., 2017). Similarly, LDN is perceived by many as a vague initiative with many unknown biophysical and socioeconomic dimensions and an insufficiently clear scientific basis (Safriel, 2017). Indeed, achieving LDN is likely to be constrained by human-social processes across multiple scales (Grainger, 2015). This suggests that understanding how neutrality can be better articulated using an SES lens, that recognises dynamic human and land system regimes and scale dynamics, can facilitate achievement of LDN targets. Humans are central to overcoming land degradation challenges as they define what losses in natural capital negatively affect social, economic and cultural systems (Sietz et al., 2017). As such, to achieve LDN requires uncovering how human agents may modify their values and decision rules to enable a shift from tendencies to 'degrade-abandon-migrate' towards actions to 'protect/restore-sustainremain' (Meyfroidt, 2013; UNCCD, 2013). There is also the need for adequate information to drive policy decisions and guide implementation actions, and to enable validation, e.g. in relation to articulating how using SES science is new and innovative in LDN contexts.

We argue that an SES approach is well suited to multi-scalar LDN efforts because: (i) it promotes ecosystem-based approaches with potential to enable restoration or rehabilitation of the stock of natural capital associated with land resources and the ecosystem services that flow from them (Aronson and Alexander, 2013); (ii) it recognises different land types and uses and their interrelationships, and considers various worldviews and associated value systems (and power dynamics) to achieve neutrality. As such, it recognises the need to negotiate trade-offs and take advantage of synergies to spur multiple-wins or no regret outcomes (Kust et al., 2017); (iii) although recording changes in terms of neutrality states requires a set of reference baselines for assessment and evaluation (Stavi and Lal, 2015), integrating SES approaches in generating LDN indicators can foster decisions in monitoring procedures based on stakeholder-led principles at the national and sub-national levels (O'Connell et al., 2013); (iv) environmental, economic, social, political, cultural and ethical characteristics need to be considered in achieving LDN targets, implying that SES can help define the enabling environment for stakeholder participation (Grainger, 2015). Promoting measures to conserve, restore and rehabilitate land-based natural capital in a SES context 
can help to adequately counterbalance expected land losses with recovery of degraded areas, as well as ensuring restoration or rehabilitation of degraded land in the same physical space where new degradation is expected to occur (Cowie et al., 2018).

In the next section, we present an SES-based LDN approach, highlighting its relevance to the neutrality agenda, as well as how SES science and practice can inspire progress towards achieving LDN outcomes.

\section{Why SES-based LDN approach?}

LDN is not a social norm and its framing is yet to recognise how people structure their thinking about neutrality issues and associated socio-political actions. Perspectives on LDN to date have been largely developed through the lens of the UNCCD Secretariat (see Safriel, 2017). This lens does not clearly articulate how to match land systems with the capabilities, willingness, behaviour and associated values and needs of land owners/holders and managers (e.g. to perceive land as a 'community' to which humans belong). Differences between place-based and process-based conceptualisation of land systems within coupled human-nature systems are yet to be clearly articulated. For example, land systems are modified through varied off-site socioecological processes (telecoupling: interlinkages/transfers across distant regions; including land grabbing, forced human displacement, etc.), as well as place-based, on-site activities of local agents impacting the systems. Yet, how to achieve LDN through SLM activities that integrate ecological, sociocultural and economic realities, as well as ethical principles, across multiple scales and ecosystems, has not been closely investigated (Chasek et al., 2015). On the basis of these gaps in knowledge, and considering increasing land degradation threats that are testing the limits of current land management approaches, it is no longer conventional to follow disciplinary lines to address LDN/governance challenges (Virapongse et al., 2016).

Similarly, because changes in land systems occur at the intersection of social and ecological systems (Schwilch et al., 2009), perspectives across social and natural science disciplines and humanities are now required to spur a new culture for land stewardship, e.g. by focusing on people as nature (Braito et al., 2017). Indeed, there is a need for innovative approaches that integrate interdisciplinarity, systemic worldviews and adaptive governance to address ecological and societal drivers of land systems changes (Table 1). Such approaches would need to be anthropocentric, placing humans as a central component of the LDN agenda. Placing land systems at the interface of human-environmental systems based on an SES approach can provide a unique platform for enhanced understanding of linkages between land use and management, and user communities. From a theoretical perspective, framing pathways to achieve neutrality under environmental change based on integrated 'socialecological systems' adds a dimension not previously explored in SLM and LDN research. This dimension considers land system dynamics within natural and social processes, as well as how changes in SES shape the functioning of land systems as a whole, and the synergies and trade-off these changes may produce (Verburg et al., 2015).

Land systems have been a central element for SES support across world regions and throughout human history (Lambin and Meyfroidt, 2011). They are the terrestrial component of the Earth system, encompassing activities relating to human use of land-based natural capital for provision of food, feed, fuel and fibres, including cultural and spiritual values (Verburg et al., 2013); and serving as an essential means of mitigation of and adaptation to environmental changes. Indeed, land systems operate at the interface of human and ecological systems, in which land is constantly modified by humans in response to changes in human perceptions/values, consumption and live styles, and opportunities offered by landbased natural capital and adaptation to environmental changes (Chasek et al., 2015). SES science conceptualises land as an open system with varied components (e.g. soil, organic carbon etc.) whose use, distribution and management (such as activities to avoid, reduce and reverse land degradation) occur within complex human society/economy and biological 
ecology domains/processes. These processes are integrated through interacting activities (e.g. management practices, adaptation/resilience building, and resource use) occurring across multiple scales and through cycles (Fischer et al., 2015). As an open system, land system components interact within a dynamic, web-like SES structure that facilitates interdependencies and feedbacks; and is influenced by direct and indirect drivers at different temporal and spatial scales (Berkes et al., 2003; Liu et al., 2007; Chapin et al., 2009). On this basis, LDN can be conceived as operating in a system of non-linear pathways and interacting feedbacks (cross-scale social and ecological feedbacks at different time-scales see Fig. 1). As such, to achieve LDN would require social and cultural institutions to use SES science to inform how people dynamically interact with land systems and the associated ecosystem services.

\section{Table 1. Characteristics of an SES-based LDN approach}

\begin{tabular}{|c|c|}
\hline Characteristics & Core interests \\
\hline Theory/worldview & $\begin{array}{l}\text { - } \quad \text { Systems thinking } \\
\text { - } \quad \text { Stakeholder-led principles } \\
\text { - Environmental cognition (capturing land as an open } \\
\text { system, humans as part of nature, drivers of } \\
\text { degradation, etc.) } \\
\text { - Local and traditional knowledge/community } \\
\text { memories }\end{array}$ \\
\hline Nature of LDN challenges & $\begin{array}{l}\text { - } \begin{array}{l}\text { Land degradation [threats/risks] } \\
\text { - }\end{array} \text { Conflicting land } \\
\text { perspectives/values } \\
\text { - } \quad \text { Broad scale (policy governance) mismatch } \\
\text { - } \text { Institutional (e.g. land tenure) constraints } \\
\text { - Integrating and balancing socio-economic issues } \\
\text { into LDN concept that is mostly defined from } \\
\text { biophysical perspective (as it is in the SDG 15.3) }\end{array}$ \\
\hline Nature of LDN opportunities & $\begin{array}{l}\text { - Mainstreaming policies and associated policy } \\
\text { procedures to maintain productive lands and limit } \\
\text { trade-offs } \\
\text { - Contributions to the broader national sustainable } \\
\text { development aspirations (e.g. reducing poverty and } \\
\text { securing food) } \\
\text { - Synergies in action for cross-scale land use } \\
\text { planning }\end{array}$ \\
\hline Participatory approaches & $\begin{array}{l}\text { - } \quad \text { Systemic worldview } \\
\text { - } \quad \text { Transdisciplinarity/interdisciplinary } \\
\text { - } \quad \text { Adaptive governance } \\
\text { - } \quad \text { Canitoring and gender-sensitive education } \\
\text { - } \quad \text { Capacity building / knowledge sharing } \\
\end{array}$ \\
\hline Target outcomes & $\begin{array}{l}\text { - Integration of actors and user communities (e.g. to } \\
\text { foster social learning and empowerment) } \\
\text { - } \quad \text { Equalisation of power dynamics } \\
\text { - Recovery of degraded areas and achievement of } \\
\text { LDN goals }\end{array}$ \\
\hline
\end{tabular}




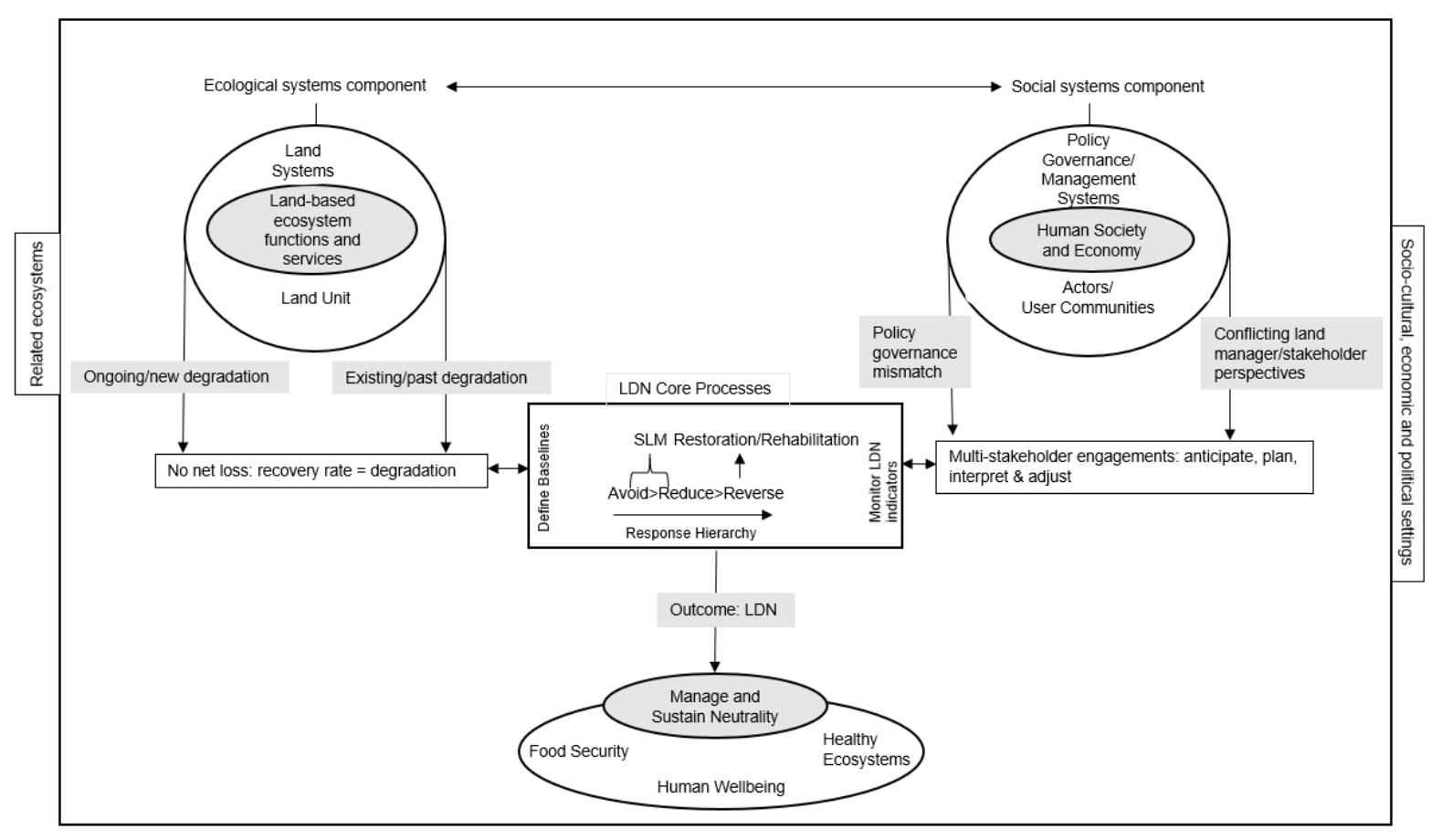

Fig. 1. SES-based LDN Framework

Using an SES-based LDN approach requires understanding: (i) land degradation drivers and pressures (i.e. interactions between ecological, social, economic, cultural and political forces) operating over varying spatiotemporal scales (Reynolds et al., 2007); (ii) the multiple land managers, actors and stakeholders affected by and implicated in degradation and restoration/rehabilitation and its/their impacts (Schwilch et al., 2009); and (iii) the research disciplines conceptualising land degradation problems and co-developing/co-implementing SLM and LDN solutions (Reed et al., 2011). This understanding can reveal: (i) several interrelated perspectives for environmental governance (related to LDN) which are rarely found in other discipline-based land governance/management approaches; (ii) what it means to consider humans as part of nature in the pursuit of LDN; and (iii) the role of baselines for tracking neutrality/when change (in land systems) lead to degradation of the resource base. These are unpacked in the following subsections.

\subsection{Interrelated perspectives underpinning an SES-based LDN approach}

\subsubsection{Systemic worldview}

An SES-based LDN perspective emphasises opportunities and limitations of interactions between informal institutions, [formal] governance systems, and cross-scale multistakeholder networks within the overarching socio-economic and political settings and related ecosystems (Berkes et al., 2003). It can serve to include nuanced global/national and local social considerations into LDN planning and implementation, enabling stakeholders to think beyond the usual constraints (see Table 1) and recognise new opportunities. A systems worldview provides academics and practitioners (from different disciplines and with different practical competencies) with a common understanding, also a common vocabulary and a logical process, for categorising issues deemed as important influences in achieving LDN plan (e.g. to understand people as nature in interconnected human-nature systems across spatial, temporal and institutional scales); it can also enable social support/attention (Virapongse et al., 2016)). By enabling an inclusive, transparent and comprehensive governance procedure, rather than the 'command-and-control governance patterns' that may otherwise characterise top-down LDN planning and implementation, SES incorporates the diverse views, value systems, and knowledge sources (scientific or experimental knowledge, 
and traditional or experiential ecological knowledge) (Palomo et al., 2011). Fostering early engagement (and the commitment) of stakeholders in real participatory processes encourages communication among land managers and users, and decision-makers in a country that allows stakeholder inclusion in decision-making processes regarding SLM and LDN, and active involvement in their implementation.

\subsubsection{Transdisciplinary approaches}

Transdisciplinarity links science and society's views of an issue; it enables co-production of practically relevant knowledge, and orients policy solutions towards multiple win ideals such as managing trade-offs and synergies. In SES science, implementing LDN via a transdisciplinary lens integrates multiple worldviews to support collaborative and systemoriented neutrality mechanisms since the complex environmental challenges associated with the causes and effects of land degradation cannot be solved from a disciplinary lens (Tress et al., 2005). By closely considering the complexities evident in land systems dynamics, an SES-informed transdisciplinary lens can help uncover ways to tackle degradation threats; and this can involve: (i) co-development of knowledge, which could include when change becomes degradation as here managers become one of the many actors (within land systems) contributing to co-learning and knowledge co-generation processes; acting as facilitators and community-builders by connecting with holders of local and traditional knowledge, rather than as external specialists with pre-defined agendas (Waltner-Toews and Kay, 2005; Alessa et al., 2015); (ii) stakeholder engagement, in, for example defining baselines/benchmarks. Integrating stakeholder needs and perceptions to form a comprehensive picture of system solutions can enable decentralisation of power, effective decision-making and co-ownership of decisions taken, and finally shared responsibilities in the implementation of decisions to achieve and maintain national LDN.

\subsubsection{Adaptive governance}

An SES-based LDN perspective situates the 'degradation-restoration/rehabilitation' balance (relating to deterioration and improvement of terrestrial ecosystems' qualities, functions and services) that LDN aims to maintain/achieve by framing LDN as a phenomenon of equilibrium of the land system adaptive governance. The key stance is that LDN can help equalise power dynamics amongst interconnected social agents, enabling flexibility in social arrangements around principles, rules, guidelines, institutions, cultures and incentives in the face of multi-scale changes (Folke et al., 2005). Because adaptive co-management of landbased socio-ecological systems is enabled within an SES approach, it also helps to design proactive steps to prevent resource (land) degradation in the first place (see Olsson et al., 2004).

\subsubsection{Monitoring systems}

Monitoring systems that cover both social and ecological variables/standards with [informative] baselines that realistically target prevailing national circumstances/visions can facilitate achievement of SLM/LDN. Adopting indicators that are specific, measurable, attainable, relevant and time-bound (i.e. SMART) enables cost-effective collection of reliable datasets to inform target setting and monitoring processes (Benson and Garmestani, 2011; Domínguez-Tejo and Metternicht, 2018). Further, understanding the factors that constitute a land systems monitoring process (e.g. social norms shaping informal structures for collaborations between different stakeholders and policy systems), managers can better monitor neutrality efforts and outcomes over the long-term, thereby also providing sound bases to adjust national implementation measures on LDN according to lessons learned and emerging issues in overall national sustainable development ambitions. In a SES context, however, this would involve managers expanding their approaches/actions to e.g. consider multiple scales (above and below the scale at which neutrality planning/monitoring is occurring) and evaluate proposed neutrality actions in light of stakeholders' perspectives and beliefs. This would imply sharing a common knowledge of LDN, and developing sound mechanisms for dissemination of information between scales to foster analyses at each 
scales and between scales. This way, SES science can provide a first step towards bringing together ecological practices and social considerations into LDN monitoring processes.

\subsubsection{Education and training}

Education and training in SES approaches are needed to develop capacities of stakeholders (mostly land managers and practitioners) and ensure sustainability of SES approaches and outcomes aligned with the LDN aims. Engaging stakeholders in co-creating land restoration/rehabilitation knowledge through SES-based approaches can foster capacities for systems thinking among land managers, change undesirable cultures and institutional norms, and integrate and guide women and youth participation in LDN (Virapongse et al., 2016). For example, the voluntary guidelines on the responsible governance of land tenure (Wehrmann, 2015) recommend improving women's access to and control over decisionmaking on land, as a way to promote food and nutrition security and to reduce poverty. This suggests acknowledgment of the impact that empowering women in controlling and taking care of land plays in stabilising community well-being, a fundamental for achieving and maintaining LDN. Training on systemic views of neutrality mechanisms can lead to more comprehensive, inter-sectoral plans for achieving LDN outcomes. Knowledge produced by integration of SES in LDN can enable managers to better predict both the social and ecological reactions of land systems, thus avoiding/minimising unintended consequences of neutrality decisions in such systems. Integrating these core SES offerings into (existing) neutrality education/knowledge systems can help facilitate the achievement of LDN.

\subsection{Conceiving humans as part of nature in the pursuit of LDN}

Operationalising LDN through an integrated SES lens is challenging but also promising in terms of enabling consideration for humans as part of nature. SES approaches with a 'humans-as-nature' focus acknowledge that humans' existence per se depends on nature, and that nature is a commodity in which humans are stakeholders (Folke, 2006). Current advocates of LDN at different levels of governance do not routinely consider "humans as part of nature", even though this integrated perspective might aid identifying, understanding and benefiting from the wide range of different connectivities, knowledge systems (scientific and traditional), and options for actions, as well as roles of different groups (e.g. women and youths), which may otherwise remain untapped, to guide policy steps towards neutrality.

An SES-based LDN approach presupposes that land use choices rely on various human motives, influenced by social beliefs and values towards land-based natural capital (Braito et al., 2017). Similarly, this approach views social-ecological feedbacks as mediated (among other factors) by human environmental cognitions (e.g. perception, interpretation, evaluation of land use changes and decision-making). In this sense, human agents can actively reevaluate their beliefs, values, and priorities/choices (e.g. through social learning) to respond to unexpected shifts in land resources (Meyfroidt, 2013). Indeed, cognitive framing of humans as nature influences the perceived role of humans in nature (Bang et al., 2017), and can be relevant in efforts to improve LDN learning.

SES epistemological orientations (e.g. along multiple sectors or disciplinary lines) can shape ecological reasoning, which in turn can motivate actions alone the response hierarchy of avoid $>$ reduce $>$ reverse land degradation. Thus, an SES perspective revealing "people as part of nature", and not "people and nature", inherently recognises that: (i) land use planning/management results from multiple human choices and decision processes, based on self-determined intentions, (ii) social-ecological pathways and feedbacks are shaped by human environmental cognitions, e.g. via perceptions, interpretation, and assessment of environmental signals, and the realisation that land resources are finite, and (iii) understanding transitions and transformations in land systems require accounting for human cognitive capabilities to change certain value/belief systems (Meyfroidt, 2013). These three core areas need to be incorporated into LDN strategies to shape the actions of the different actors involved in avoiding and combating land degradation. 
Likewise, embedding local and traditional ecological knowledge (TEK) (e.g. to reflect the roles of human groups in nature), in SES analysis for LDN planning can better support achieving and sustaining a secure and well-functioning environment (see Berkes, 2009; Gómez-Baggethun et al., 2013). TEK is a body of knowledge, values and practices about humans' connections with one another and with the natural world (Berkes et al., 2000; Houde, 2007). Although such knowledge is passed on through generations by cultural transmission, it is mainly acquired through direct experiences/knowledge of the environment, e.g. through land-related livelihood practices and maintenance of active linkages with places/nature (Davidson-Hunt and Berkes, 2003).

As TEK comprises systems to classify land-based natural capital, monitor land use changes, understand and assess degradation/baselines, transmit and enforce restoration/rehabilitation practices, and adjust them when needed (Meyfroidt, 2013), its inclusion in an SES for LDN strategy can facilitate identification of feedbacks/signals from land changes, e.g. through cultural processes of social learning (Rist et al., 2003). Social learning, in this context, offers a way to acquire and update cognitions about humans' connectedness to nature through social interactions occurring within wider communities of practice (Reed et al. 2010).

\subsection{Baselines for tracking neutrality using an SES lens}

An important aspect of LDN's approach to land degradation threats is the dilemma around the notion of baselines. Baselines in LDN contexts represent the frame of reference against which neutrality can be assessed across temporal and spatial dimensions. Putting a landscape to a new altered use to serve human needs (i.e. rehabilitation or reclamation) or ambitions to return land ecosystems to their former quasi natural conditions (i.e. restoration) targets neutrality in some form (Akhtar-Schuster et al., 2017). Neutrality emphasises stability or increase in land quality/quantity, yet it is unclear which state serves as a reference point for defining 'stability', 'increase' or 'decrease' in land resources, as well as who should be involved in the decision.

Conceptually, neutrality requires that there is no net loss of land-based natural capital between time zero (2015 - the year when the UNCCD adopted LDN and the SDGs were agreed) and the SDG target date of 2030. A LDN baseline is therefore the 'former state' or 'initial value' of each of the (biophysical) indicators (i.e. land cover, productivity and carbon storage) used to monitor LDN (Orr et al., 2017). The baseline values of the indicators at the start of the policy implementation ( $\left.\mathrm{t}_{0}\right)$ are (to be) compared to the values measured at the target date $\left(t_{1}\right)$ to determine the change in land-based natural capital (Cowie et al., 2018). As the goal of LDN is no net loss, the neutrality target is assumed equal to the baseline, i.e. $t_{1}=$ $t_{0}$. As such, any change below this baseline is termed degradation - and baselines in this sense encompass baseline period and baseline in terms of land amount and quality.

The argument then becomes whether this is actually an appropriate baseline for tracking change. While neutrality is the minimum objective, different regions may decide to set more ambitious targets given that loads of degradation has taken place long before 2015. For example, aiming for lands in dryland Africa to be kept indefinitely within baseline values of the indicators at the start of the implementation of the LDN policy seems to not make a great deal of sense as it is acknowledged that these lands were already heavily degraded. While the baseline concept is somewhat problematic for establishing neutrality targets for all countries, historical/traditional knowledge and community memories (more broadly conceived to include SES processes), including pre-existing data signalling what land quantity/quality has been in the past for specific regions, will remain essential for setting appropriate baselines for assessing neutrality metrics, such as land cover change, net primary production and soil organic carbon, that go further back than 2015 (see Alagona et al., 2012; Orr et al., 2017). Indeed, more favourable targets to improve and maintain the land-based natural capital should be needs-based and context-specific, e.g. drawing on the 
five interrelated perspectives underpinning an SES-based LDN approach presented in Section 3.1. In this way, baseline setting within the SES contexts can be tailored to: country characteristics (e.g. considering trends in ecosystem properties and anthropogenic impacts); land market conditions; and adaptive co-management settings influencing stakeholder engagement (e.g. where land managers forge new collaborations with conservation professionals, development practitioners, social scientists and local leaders, as well as encouraging the participation of the general public) to track degradation reductions.

Difficulties inherent to identifying baselines for maintaining environmental integrity of neutrality programmes should not discourage the adoption of SES science, e.g. in defining neutrality goals, but rather challenge land managers to incorporate more sophisticated participatory analyses of the biophysical environment and socioeconomic aspects of LDN to account for the complexity and variation of degradation/change over time. While it is crucial that countries agree to use the same baseline period for tracking progress, e.g. to enhance comparability and assessment at the global scale, recasting the LDN baseline of $t_{1}=t_{0}$ to include SES knowledge shows a way to track multifaceted land changes over time, offering a middle ground where the years before and after to may inform the desirable land ecosystems of the future. An SES-based LDN approach may be imperfect as a model for the future, but it is a useful guide for tracking and understanding degradation in a human-nature system where an aggregation of values, decision rules and cultures determine progress along neutrality baseline operationalisation where a country needs to justify its target.

In sum, baselines enable tracking of progress towards neutrality and are essential for distinguishing "between lands that are candidates for reducing their ongoing degradation (second class) and lands that are degraded and would be subjected to restoration efforts (third class) for offsetting further degradation. First class land is that used sustainably (in a pristine condition) and whose productivity could serve as a baseline when measures to prevent or to reduce degradation are adopted" (Chasek et al., 2015, p. 12). Such land could also include quasi-intact natural sites, which could serve as a baseline especially when implementing measures to prevent any land degradation, or for restoration measures which are aimed at returning an ecosystem to a quasi-original condition (Akhtar-Schuster et al., 2017).

\section{Conclusions}

Although understanding dynamic human social and economic processes can contribute substantially to LDN success, gaining an understanding of what kind of social-ecological factors matter, why they matter, and how distant social systems undermine the capacity of local institutions to regulate land systems has proved challenging (e.g. for stakeholders who must be included in a SES-based LDN planning/action from the outset). Similarly, incorporating social data into LDN planning requires spatially-explicit datasets to enable socio-cultural priorities to be distinctly articulated in spatiotemporal terms. Further, the process of systematic LDN planning tends to be static, prescriptive, and often technical. As such, when planning is not articulated in "measurable" terms, the scope to include SES dynamism, varied preferences/values, and to consider trade-offs among different LDN objectives can be limited (Verburg et al., 2015).

Little guidance exists on how to move from recognition of the need to address SES aspects of land systems in LDN planning, to actually incorporating these into planning. The LDN conceptual framework suggests LDN planning to occur within established national land use planning models; which can be of concern when countries adopt a decentralised territorial/land planning model. In most countries where land use planning is a decentralised process, mainstreaming the environmental dimension into social and economic sectors is slow, and suffers from lack of competencies from the development operators that help the elaboration of sustainable development strategy at the local level (Chazée et al, 2017). In 
this regard, LDN could foster cross-sectoral environmental mainstreaming, by focusing more on knowledge sharing and accounting for diverse perceptions of environmental resources and their use.

The advantages of a systematic SES-based LDN approach remain evident: (i) it serves as a starting point to infuse a more comprehensive (and transparent) view of social and ecological considerations, and trade-offs, into LDN; (ii) it emphasises the monitoring (and further iteration) of social and ecological effects of measures introduced to achieve LDN; (iii) it emphasises multi-scale dynamics, interactions and processes, which are essential to reorient LDN planning beyond actions that are often perceived as occurring in a static context; (iv) it enables accounting for inclusiveness of participation, gender-sensitivity and coimplementation, and (v) it can help to develop a new culture for pursuing neutrality goals. Developing such cultural aspects can advance systemic processes that overcome current degradation challenges. Finally, by adopting new mechanisms/cultures for LDN embedded in SES, land managers can re-negotiate the context for how LDN science is done, while also pursuing/achieving the broader land system resilience goals.

Indeed, the quest for the 'neutrality state' offers a useful opportunity to integrate SES theory and application of land management to achieve and maintain both systems resilience and neutrality outcomes. Further, it enables knowledge generation (via integration of data from various humanities and natural and social science disciplines) and the formulation of sustainable resource management solutions through understanding of context-based land potentials.

Overall, a shift in the LDN science and practice will be needed to incorporate SES thinking into neutrality actions - one that ascribes the same value to human and social considerations as to ecological ones, and that seeks to integrate the two across multiple scales and ecosystems. To make the process cost-effective and sustainable, and to ensure that assessments are linked to future planning, community groups and stakeholders must take a leading role in the design and implementation of LDN strategies and policies. SES should inform the process for tracking LDN (baseline setting) and regulating land use and management decisions, considering the perceptions and realities of indigenous and local land users through their direct involvement in decision making.

\section{References}

Akhtar-Schuster, M., Stringer, L., Erlewein, A., Metternicht, G., Minelli, S., Safriel, U., Sommer, S, 2017. Unpacking the concept of land degradation neutrality and addressing its operation through the Rio Conventions. Journal of Environmental Management 195, Part 1: 4-15.

Alagona, P., Sandlos, J., Wiersma, Y, 2012. Past imperfect: Using historical ecology and baseline data for conservation and restoration projects in North America. Environmental Philosophy 9 (1): 49-70.

Alessa, L., Kliskey, A., Altaweel, M., Barton, M., Bankes, S., Bondizio, E., Brown, D., Feddema, J., Grier, C., Liu, J., Moran, E. and other, 2015. Best Practices for Integrating Social Sciences into Social Ecological Systems Science: future Directions for Building a More Resilient America. In: Center for Resilient Communities. University of Idaho, Moscow, Idaho, USA.

Armitage, D.R., Plummer, R., Berkes, F., Arthur, R.I., Charles, A.T., Davidson-Hunt, I.J., Diduck, A.P., Doubleday, N.C., Johnson, D.S., Marschke, M. and others, 2008. Adaptive comanagement for social-ecological complexity. Front. Ecol. Environ. 7 (2), 95-102. 
Aronson, J., Alexander, S, 2013. Ecosystem restoration is now a global priority: time to roll up our sleeves. Restoration Ecology 21 (3): 293-296.

Bang, M., Medin, D. and Atran, S. 2007. Cultural mosaics and mental models of nature. PNAS 104(35):13868-13874.

Barkemeyer, R., Stringer L. C., Hollins, J. A., Josephi, F. 2015. Corporate reporting on solutions to wicked problems: sustainable land management in the mining sector. Environmental Science \& Policy 48: 196-209.

Benson, M.H., Garmestani, A.S, 2011. Embracing panarchy, building resilience and integrating adaptive management through a rebirth of the national environmental policy act. Environ. Manag. 92 (5), 1420-1427.

Berkes, F, 2009. Indigenous ways of knowing and the study of environmental change. Journal of the Royal Society of New Zealand 39:151-156.

Berkes, F., Colding, J., Folke, C 2000. Rediscovery of traditional ecological knowledge as adaptive management, Ecological Applications 10, 1251-1262.

Berkes, F., Colding, J., Folke, C., 2003. Navigating Social-ecological Systems: Building Resilience for Complexity and Change. Cambridge University Press, Cambridge, UK.

Born, S.M., Sonzogni, W.C. 1995. Integrated environmental management: strengthening the conceptualization. Environmental Management 19 (2): 167-181.

Braito, M. T., Bock, K., Flint, C., Muhar, A., Muhar, S., Penker, M, 2017. Human-nature relationships and linkages to environmental behaviour. Environmental Values 26: 365-389.

Chapin, F.S., Folke, C., Kofinas, G.P., 2009. A Framework for Understanding Change. Principles of Ecosystem Stewardship. Springer, New York, USA.

Chasek, P., Safriel, U., Shikongo, S., Fuhrman, V. F, 2015. Operationalizing zero net land degradation: the next stage in international efforts to combat desertification? Journal of Arid Environ 112:5-13.

Chazée L., Requier-Desjardins M., Ghouat N., El Debs R., 2017. La planification locale, outil de durabilité environnementale: le cas des zones humides méditerranéennes. New Medit,16(1): 62-72; http://newmedit.iamb.it/edizioni_new_medit,229,229,2017,166,1095,laplanification-locale-outil-de-durabilite-environnementale-:-le-cas-des-zones-humidesmediterraneennes-.htm

COMEST. 2005. The Precautionary Principle. World Commission on the Ethics of Scientific Knowledge and Technology (COMEST). http://unesdoc.unesco.org/images/0013/001395/139578e.pdf (accessed 11.11.2017).

Cowie, A.L., Orr, B.J., Castillo Sanchez, V.M., Chasek, P., Crossman, N.D., Erlewein, A., Louwagie, G., Maron, M., Metternicht, G.I., Minelli, S., Tengberg, A.E., Walter, S., Welton, S. 2018. Land in balance: The scientific conceptual framework for Land Degradation Neutrality. Environmental Science and Policy 79: 25-35.

Davidson-Hunt, I., Berkes, F., 2003. Learning as you journey: Anishinaabe perception of social-ecological environments and adaptive learning. Conservation Ecology, 8: 5. 
Domínguez-Tejo, E., Metternicht, G., 2018. Poorly-designed goals and objectives in resource management plans: Assessing their impact for an Ecosystem-Based Approach to Marine Spatial Planning. Marine Policy 88: 122-131.

European Commission. 2000. Communication on the Precautionary Principle. Commission of the European Communities, 1-28. Retrieved from http://eurlex.europa.eu/legalcontent/EN/TXT/PDF/?uri=CELEX:52000DC0001\&from=EN (accessed 10.1.2018)

Fischer, J., Gardner, T., Bennett, E., Balvanera, P., Biggs, R., Carpenter, S., Daw, T and Folke, C. and others 2015. Advancing sustainability through mainstreaming a socialecological systems perspective. Current Opinion in Environmental Sustainability 14: 144149.

Folke, C., 2006. Resilience: the emergence of a perspective for social-ecological systems analyses. Global Environmental Change 16 (3): 253-267.

Folke, C., Hahn, T., Olsson, P., Norberg, J. 2005. Adaptive governance of social-ecological systems. Annu. Rev. Environ. Resour. 30: 441-473.

Gnacadja, L., 2012. From combating desertification in drylands to global land degradation neutrality and the Zero Net Land Degradation. In: Proceedings of the 4th International Conference on Drylands, Deserts \& Desertification. Ben Gurion University of the Negev, Sde-Boqer, pp. 64-65.

Gómez-Baggethun, E., Corbera, E., Reyes-García, V., 2013. Traditional ecological knowledge and global environmental change: research findings and policy implications. Ecology and Society 18(4): 72.

Grainger, A. 2015. Is land degradation neutrality feasible in dry areas? Journal of Arid Environments 112: 14-24.

Houde, N. 2007. The six faces of traditional ecological knowledge: challenges and opportunities for Canadian co-management arrangements. Ecology and Society 12(2): 34.

Kust, G., Andreeva, O. and Cowie, A. 2017. Land Degradation Neutrality: Concept development, practical applications and assessment. Journal of Environmental Management 195: 16-24.

Lal, R., Safriel, U., Boer, B., 2012. Zero Net Land Degradation: A New Sustainable Development Goal for Rio+ 20. A Report Prepared for the Secretariat of the United Nations Convention to Combat Desertification. Online at http://www.unccd.int/ Lists/SiteDocumentLibrary/secretariat/2012/Zero\%20Net\%20Land\%20Degradation\%20Rep ort\%20UNCCD\%20May\%202012\%20background.pdf. (accessed 14.1.2018).

Lambin, E. F., Meyfroidt, P. 2010. Land use transitions: socio-ecological feedbacks versus socio-ecological change. Land Use Policy, 27: 108-118.

Lambin, E.F., Meyfroidt, P. 2011. Global land use change, economic globalization, and the looming land scarcity. PNAS 108: 3465-3472.

Leslie, H., Basurto, X., Nenadovic, M., Sievanen, L., Cavanaugh, K., Cota-Nieto, J., Erisman, B., Finkbeiner, E., Hinojosa-Arango, G., Moreno-Báez, M., Nagavarapu, S., Reddy, $\mathrm{S}$. and others, 2015. Operationalizing the social-ecological systems framework to assess sustainability. PNAS 112 (19): 5979-5984. 
Liu, J., Dietz, T., Carpenter, S.R., Alberti, M., Folke, C., Moran, E., Pell, A.N., Deadman, P., Kratz, T., Lubchenco, J., others, 2007. Complexity of coupled human and natural systems. Science 317 (5844), 1513-1516.

Liu, J.Q., Hull, V., Batistella, M., DeFries, R., Dietz, T., Fu, F., Hertel, T.W., Izaurralde, R. C., Lambin, E.F., Li, S., Martinelli, L.A., McConnell, W., Moran, E.F., Naylor, R., Ouyang, Z., Polenske, K.R., Reenberg, A., de Miranda Rocha, G., Simmons, C.S., Verburg, P.H., Vitousek, P.M., Zhang, F., Zhu, C. 2013. Framing sustainability in a telecoupled world. Ecology and Society 18(2): 26.

Margerum, R. D. 1995. Integrated Environmental Management: Moving from Theory to Practice. Journal of Environmental Planning and Management, 38(3): 371-392.

Margerum, R.D. 1999. Integrated environmental management: the foundations for successful practice. Environmental Management 24 (2): 151-166.

O'Connell, B.A.D., Raison, J., Hatfield-Dodds, S., Wiedmann, T., Cowie, A., Littleboy, A., Clark, M. 2013. Navigating sustainability: Measurement, evaluation and action. Paper prepared by CSIRO for the World Economic Forum Global Agenda Council on Measuring Sustainability CSIRO, p. 104. Online at https://publications.csiro.au/rpr/download? pid=csiro: EP1311726\&dsid=DS8. (accessed 05.1.2018)

Olsson, P., Folke, C., Berkes, F., 2004. Adaptive co-management for building resilience in social-ecological systems. Environmental Management 34 (1): 75-90.

Orr, B. J, Cowie, A. L, Castillo Sanchez V. M, Chasek, P., Crossman, N. D, Erlewein, A., Louwagie, G., Maron, M., Metternicht, G.I, Minelli, S., Tengberg, A. E., Walter, S., Welton, S., 2017. Scientific conceptual framework for land degradation neutrality. A Report of the Science-Policy Interface. United Nations Convention to Combat Desertification (UNCCD), Bonn, Germany.

Ostrom, E., 2009. A general framework for analysing sustainability in social-ecological systems. Science 325: 419-422.

Ostrom, E., 2010. Polycentric systems for coping with collective action and global environmental. Global Environmental Change 20, 550-557.

Palomo I, Martin-Lopez B, Lopez-Santiago C, Montes C., 2011. Participatory scenario planning for protected areas management under the ecosystem services framework: the Donana social-ecological system in Southwestern Spain. Ecology and Society16(1): 23.

Reed, M. S., Stringer, L. C., Dougill, A. J, Perkins, J. S, Atlhopheng, J. R, Mulale, K., Favretto, N., 2015. Reorienting land degradation towards sustainable land management: linking sustainable livelihoods with ecosystem services in rangeland systems. Journal of Environmental Management 151: 472-485.

Reed, M. S., Stringer, L. C., 2016. Land degradation, desertification and climate change: anticipating, assessing and adapting to future change. Routledge: Oxon, UK.

Reed, M. S., Buenemann, M., Atlhopheng, J., Akhtar-Schuster, M., Bachmann, F., Bastin, G., Bigas, H., Chanda, R., Dougill, A., Essahli, W., 2011. Cross-scale monitoring and assessment of land degradation and sustainable land management: a methodological framework for knowledge management. Land Degradation and Development 22 (2) 261271. 
Reed, M.S., Evely, A.C., Cundill, G., Fazey, I., Glass, J., Laing, A., Newig, J., Parrish, B., Prell, C., Raymond, C., and Stringer, L.C. 2010. What is social learning? Ecology and Society, $15, \mathrm{r} 1$.

Reynolds, J., Smith, D.., Lambin, E., Turner, B., Mortimore, M., Batterbury, S., Downing, T., Dowlatabadi, H., Ferna'ndez, R., Herrick, J., 2007. Global desertification: building a science for dryland development. Science 316 (5826) 847-851.

Rist, S., Burgoa, F., and Wiesmann, U., 2003. The role of social learning processes in the emergence and development of Aymara land use systems, Mountain Research and Development, 23, 263-270.

Ritsema, C., van Lynden, G., Jetten, V., de Jong, S., 2005. Degradation. Encyclopedia of Soils in the Environment, 370-377.

Safriel, U., 2017. Land degradation neutrality in drylands and beyond - where has it come and where does it go. Silva Fennica 15 (1B): 1-19.

Schwilch, G., Bachmann, F., Liniger, H., 2009. Appraising and selecting conservation measures to mitigate desertification and land degradation based on stakeholder participation and global best practices. Land Degradation and Development 20 (3) 308-326.

Sietz, D., Fleskens, L., Stringer, L., 2017. Learning from non-linear ecosystem dynamics is vital for achieving land degradation neutrality. Land Degradation and Development 28: 23082314.

Sims, N.C., Green, C., Newnham, G.J., England, J.R., Held, A., Wulder, M.A., Herold, M., Cox, S.J.D., Huete, A.R., Kumar, L., Viscarra Rossel, R.A., Roxburgh, S.H., \& McKenzie, N.J. 2017. Good Practice Guidance. SDG Indicator 15.3.1, Proportion of land that is degraded over total land area (p. 115). United Nations Convention to Combat Desertification (UNCCD), Bonn, Germany. http://www2.unccd.int/sites/default/files/relevant-links/201710/Good\%20Practice\%20Guidance_SDG\%20Indicator\%2015.3.1_Version\%201.0.pdf. (accessed 07.01.2018)

Stavi, I., Lal, R., 2015. Achieving zero net land degradation: challenges and opportunities. Journal of Arid Environments 112: 44-51.

Torday, J.S., Miller, W.B., 2015. Man is integral with nature. Minding Nature Journal 8 (1): 37-44.https://www.humansandnature.org/filebin/pdf/minding nature/january 2015/Final Minding-Nature-v8n1-January_2015_2.pdf.

Tress, G., Tress, B., Fry, G., 2005. Clarifying integrative research concepts in landscape ecology. Landsc. Ecol. 20 (4), 479-493.

Turner, B. L., P. Matson, J. J. McCarthy, R. W. Corell, L. Christensen, N. Eckley, G. Hovelsrud-Broda, J. X. Kasperson, R. E. Kasperson, A. Luers, M. L. Martello, S. Mathiesen, R. Naylor, C. Polsky, A. Pulsipher, A. Schiller, H. Selin, N. Tyler. 2003. Illustrating the coupled human-environment system for vulnerability analysis: three case studies. PNAS 100 (14):8080-8085.

UNCCD 2013. A Stronger UNCCD for a Land-Degradation Neutral World. UNCCD Secretariat Issue Brief. UN Convention to Combat Desertification, Bonn.

UNCCD, 2017. UNITED NATIONS CONVENTION TO COMBAT DESERTIFICATION IN THOSE COUNTRIES EXPERIENCING SERIOUS DROUGHT AND/OR 


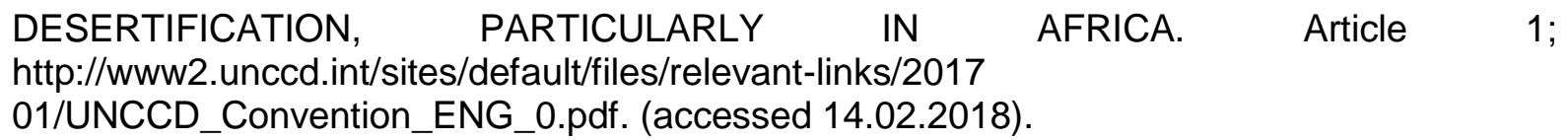

UNCCD. 2016. Land in balance. The scientific conceptual framework for land degradation neutrality (LDN). Science-Policy Brief 02. September 2016, United Nations Convention to Combat Desertification (UNCCD), Science-Policy Interface, Bonn, Germany.

Verburg, P. Crossman, N., Ellis, E., Heinimann, A., Hostert, P., Mertz, O., Nagendra, H., others. 2015. The Anthropocene 12: 29-41.

Verburg, P.H., Erb, K. H., Mertz, O., Espindola, G., 2013. Land System Science: between global challenges and local realities. Current Opinion in Environ. Sustain. 5, 433-437.

Virapongse, A., Brooks, S., Metcalf, E., Zedalis, M., Gosz, J., Kliskey, A., Alessa, L. 2016. A social-ecological systems approach for environmental management. Journal of Environmental Management 178: 83-91.

Waltner-Toews, D., Kay, J., 2005. The evolution of an ecosystem approach: the diamond schematic and an adaptive methodology for ecosystem sustainability and health. Ecol. Soc. $10(1), 38$.

Wehrmann, B., 2015. Voluntary Guidelines on the Responsible Governance of Tenure of Land, Fisheries and Forests in the Context of National Food Security" (VGGT) - from a Gender Perspective. Analysis and Policy Recommendations. (Eds. Brot für die Welt and Oxfam Deutschland e.V.). https://www.gltn.net/index.php/publications/publications/partnerpublications/642-voluntary-guidelines-on-the-responsible-governance-of-tenure-of-landfisheries-and-forests-in-the-context-of-national-food-security-vggts-from-a-genderperspective.

Westley, F., Olsson, P., Folke, C., Homer-Dixon, T., Vredenburg, H., Loorbach, D., Thompson, J., ans Nilsson, M., Lambin, E., Sendzimir, J., others, 2011. Tipping toward sustainability: emerging pathways of transformation. Ambio 40 (7), 762-780. 